\title{
Lung function and indicators of exposure to indoor and outdoor particulate matter among asthma and COPD patients
}

J J de Hartog, J G Ayres, A Karakatsani, et al.

Occup Environ Med 2010 67: 2-10 originally published online September 6, 2009

doi: 10.1136/oem.2008.040857

Updated information and services can be found at:

http://oem.bmj.com/content/67/1/2.full.html

\begin{tabular}{cl}
\hline These include: \\
References & $\begin{array}{l}\text { This article cites } 22 \text { articles, } 7 \text { of which can be accessed free at: } \\
\text { http://oem.bmj.com/content/67/1/2.full.html\#ref-list-1 }\end{array}$ \\
$\begin{array}{c}\text { Email alerting } \\
\text { service }\end{array}$ & $\begin{array}{l}\text { Receive free email alerts when new articles cite this article. Sign up in the } \\
\text { box at the top right corner of the online article. }\end{array}$ \\
\hline
\end{tabular}

Notes

To order reprints of this article go to:

http://oem.bmj.com/cgi/reprintform

To subscribe to Occupational and Environmental Medicine go to:

http://oem.bmj.com/subscriptions 


\title{
Lung function and indicators of exposure to indoor and outdoor particulate matter among asthma and COPD patients
}

\author{
$\mathrm{J} J$ de Hartog, ${ }^{1} \mathrm{~J} \mathrm{G}$ Ayres, ${ }^{2} \mathrm{~A}$ Karakatsani, ${ }^{3} \mathrm{~A}$ Analitis, ${ }^{4} \mathrm{H}$ ten Brink, ${ }^{5} \mathrm{~K}$ Hameri, ${ }^{6}$ \\ R Harrison, ${ }^{7}$ K Katsouyanni, ${ }^{4}$ A Kotronarou ${ }^{8}{ }^{8}$ Kavouras, ${ }^{8}$ C Meddings, ${ }^{7}$ J Pekkanen, $,{ }^{9}, 10$ \\ G Hoek ${ }^{1}$
}

${ }^{1}$ University of Utrecht, Institute for Risk Assessment Sciences, Environmental and Occupational Health Division, Utrecht, the Netherlands; ${ }^{2}$ Institute of Occupational \& Environmental Medicine, University of Birmingham, Birmingham, UK;

${ }^{3}$ National and Kapodistrian University of Athens, 2nd Department of Respiratory Medicine, Chaidari, Greece;

${ }^{4}$ National and Kapodistrian University of Athens,

Department of Hygiene and Epidemiology, Athens, Greece;

${ }^{5}$ Energy Research Center of the Netherlands, Business Unit ECN clean Fossil Fuels, Petten, the Netherlands; ${ }^{6}$ University of Helsinki, Department of Physics, Helsinki, Finland; ${ }^{7}$ University of Birmingham, Division of

Environmental Health and Risk Management, Birmingham, UK

${ }^{8}$ National Observatory Athens,

Institute for Environmental

Research and Sustainable

Development, Athens, Greece;

${ }^{9}$ National Public Health Institute, Unit of Environmental

Epidemiology, Kuopio, Finland;

${ }^{10}$ School of Public Health and

Clinical Nutrition, University of

Kuopio, Finland

\section{Correspondence to:}

Gerard Hoek, IRAS, Utrecht University, PO Box 80178, 3508

TD Utrecht, the Netherlands; g.hoek@uu.nl

Accepted 9 June 2009 Published Online First

6 September 2009

\section{ABSTRACT}

Objectives: Misclassification of exposure related to the use of central sites may be larger for ultrafine particles than for particulate matter $\leqslant 2.5 \mu \mathrm{m}$ and $\leqslant 10 \mu \mathrm{m}$ $\left(\mathrm{PM}_{2.5}\right.$ and $\left.\mathrm{PM}_{10}\right)$ and may result in underestimation of health effects. This paper describes the relative strength of the association between outdoor and indoor exposure to ultrafine particles, $\mathrm{PM}_{2.5}$ and $\mathrm{PM}_{10}$ and lung function. Methods: In four European cities (Helsinki, Athens, Amsterdam and Birmingham), lung function (forced vital capacity (FVC), forced expiratory volume in 1 second $\left(\mathrm{FEV}_{1}\right)$ and peak expiratory flow (PEF)) was measured three times a day for 1 week in 135 patients with asthma or chronic obstructive pulmonary disease (COPD), covering study periods of $>1$ year. Daily concentrations of particle number, $\mathrm{PM}_{2.5}$ and $\mathrm{PM}_{10}$ were measured at a central site in each city and both inside and outside the subjects' homes.

Results: Daily average particle number concentrations ranged between 2100 and 66100 particles $/ \mathrm{cm}^{3}$. We found no association between $24 \mathrm{~h}$ average particle number or particle mass concentrations and FVC, FEV and PEF. Substituting home outdoor or home indoor concentrations of particulate air pollution instead of the central site measurements did not change the observed associations. Analyses restricted to asthmatics also showed no associations.

Conclusions: No consistent associations between lung function and $24 \mathrm{~h}$ average particle number or particle mass concentrations were found in panels of patients with mild to moderate COPD or asthma. More detailed exposure assessment did not change the observed associations. The lack of association could be due to the high prevalence of medication use, limited ability to assess lagged effects over several days or absence of an effect.

Numerous studies have reported short-term effects of outdoor air pollution on mortality, hospital admissions for cardiopulmonary disease, respiratory symptoms, lung function and changes in cardiac function. ${ }^{1}$ Particulate matter, usually that $\leqslant 10 \mu \mathrm{m}$ in aerodynamic diameter $\left(\mathrm{PM}_{10}\right)$ is the main driver of the observed health effects. Toxicological studies have shown that ultrafine particles ( $<100 \mathrm{~nm}$ in aerodynamic diameter) may be most toxic. ${ }^{23}$ The ultrafine fraction accounts for $<1 \%$ of the mass of particulate matter, but the greater proportion in terms of numbers. ${ }^{245}$ Ultrafine particles may be harmful because of the large numbers, the large (reactive) surface area,

\section{What this paper adds}

- Short-term increases in particulate matter air pollution have been associated with decreased lung function in children and adults.

- Some epidemiological studies found stronger associations between central site measurements of ultrafine particles and lung function decrements than with particulate matter $\leqslant 10 \mu \mathrm{g}\left(\mathrm{PM}_{10}\right)$ but other studies reported similar or smaller effects.

- Some of these inconsistencies may be due to more exposure misclassification for ultrafine particles than for $\mathrm{PM}_{10} /$ particulate matter $\leqslant 2.5 \mu \mathrm{g}\left(\mathrm{PM}_{2.5}\right)$, related to using a central site.

- No consistent associations between lung function and $24 \mathrm{~h}$ average particle number or particle mass concentrations were found in panels of patients with mild to moderate chronic obstructive pulmonary disease or asthma.

- More detailed exposure assessment by using home outdoor and home indoor concentration levels of ultrafine particles, $\mathrm{PM}_{10}$ and $\mathrm{PM}_{2.5}$ instead of central site measurements did not change the lack of associations.

more effective deposition in the lungs ${ }^{6}$ and their ability to penetrate into the interstitium of the lungs.

There are few epidemiological studies on the effects of ultrafine particles on respiratory health..$^{8-13}$ Some studies suggested that ultrafine particles were more strongly associated with lung function decrements than $\mathrm{PM}_{10}{ }^{11}$ but other studies reported similar $^{812}$ and even smaller effects of ultrafine particles compared with $\mathrm{PM}_{10}{ }^{10}$

Some of these inconsistencies may be due to differences in exposure assessment which usually relied on central site measurements of air pollution. While there is evidence that central site concentrations of $\mathrm{PM}_{2.5}$ and $\mathrm{PM}_{10}$ are a good approximation of personal exposure ${ }^{14}$ it is largely unknown how well ultrafine particle measurements at a fixed outdoor site represent personal exposure. ${ }^{5}$ If exposure misclassification is larger for ultrafine particles than for $\mathrm{PM}_{10} / \mathrm{PM}_{2.5}$, more underestimation of potential health effects in epidemiological studies for ultrafine particles may occur. 
The Relationship between Ultrafine and fine Particulate matter in Indoor and Outdoor air and respiratory Health (RUPIOH) study was designed to assess the impact of more detailed exposure assessment, by comparing the health effects related to simultaneous measurements of fine and ultrafine particles at a central site, inside and directly outside study participants' homes. In this paper, the relative strength of the association between outdoor and indoor exposure to fine and ultrafine particles and lung function in subjects with asthma or chronic obstructive pulmonary disease (COPD) is described. Relationships between central site outdoor, residential outdoor and indoor concentrations have been published previously. ${ }^{15} 16$

\section{MATERIALS AND METHODS}

\section{Study design}

A multicentre study was conducted from October 2002 to March 2004 in Helsinki (Finland), Athens (Greece), Amsterdam (the Netherlands) and Birmingham (UK). During the whole study period a reference site in each city was used to monitor particle mass and particle number concentration on a daily basis. At various locations covering the entire metropolitan area, homes of subjects with either asthma or COPD were selected. Air pollution monitoring was successively performed for 1 week in the selected homes indoors (living room) and directly outdoors. During this week, respiratory health was characterised by spirometry, a symptom diary, collection of exhaled breath condensate and urine sample for CC16 determination. This paper focuses on lung function. Forced vital capacity (FVC), forced expiratory volume in 1 second $\left(\mathrm{FEV}_{1}\right)$ and peak expiratory flow (PEF) were measured three times per day with data storage spirometers. Mixed models were used to assess the association between $24 \mathrm{~h}$ average particle concentrations from the central site, home outdoor and home indoor locations and lung function.

\section{Study population}

The inclusion criteria were age $\geqslant 35$ years, a doctor diagnosis of asthma or COPD and having experienced chronic respiratory symptoms in the previous 12 months. Subjects unable to perform a satisfactory spirometry test and severe patients, defined as using bronchodilating reliever medications for $>3$ times a day or using nebulised bronchodilators or long-term oxygen treatment, were excluded. Preference was given to nonworking subjects to eliminate potential confounding by occupational exposures to airborne particles and to approximate personal exposure closer by the indoor measurements. We attempted to select non-smokers living in a non-smoking household to avoid confounding by environmental tobacco smoke. Although recruitment methods differed across the four centres, the same screening questionnaire was used to check eligibility.

In Finland, subjects were selected from the Helsinki Metropolitan Area through advertisements in the respiratory patient association magazine, newspapers and notice boards of pulmonary disease clinics of four major hospitals. Eligible subjects were interviewed by telephone and invited to an information session.

In Greece, patients from the Athens greater area were recruited through local chest physicians. Eligible subjects were contacted by phone. Those willing to participate were visited by investigators to check inclusion criteria.

In the Netherlands, subjects across the city of Amsterdam were approached by distributing 10000 information letters and through a call for participation in a local newspaper. Eligible subjects were visited by investigators to check inclusion criteria.

In the UK, subjects living in the greater area of Birmingham were selected from the Chest Research Institute database of respiratory patients at Birmingham Heartlands Hospital, restricted to those who had given written consent to be approached for research studies. Local general practices were approached as well as targeted recruitment from the Birmingham Chest Clinic. Finally, an advertisement was placed in a local newspaper.

Medical ethical clearance was acquired from the local medical ethics committees in all centres before the start of the recruitment. Written informed consent was obtained from each subject.

\section{Lung function}

The Diary Card (Micro Medical Ltd., Rochester, UK) was used for lung function monitoring. This device is a compact, batteryoperated and portable data-recording spirometer measuring FVC, $\mathrm{FEV}_{1}$ and PEF. The spirometer uses a turbine to measure flows, so no adjustment to volumes at body temperature and pressure saturated (BTPS) is necessary. The instrument fulfils American Thoracic Society requirements ${ }^{17}$ and has been tested in previous studies. ${ }^{18} 19$ Advantages compared with the frequently used Mini Wright meters (Clement Clarke International Ltd, London, UK) are that the subject does not have to record data and that FVC and $\mathrm{FEV}_{1}$ data are obtained.

During the first home visit the subjects were instructed on how to perform the forced expiratory manoeuvre. The subjects were asked to perform three tests a day (morning, lunch and evening) during the monitoring week. The spirometer was programmed for a morning test between 7:00 and 10:00, a lunch test between 12:00 and 14:00, and an evening test between 20:00 and 24:00. One test outside these time windows was allowed. At two check visits, feedback was given to the subjects. A test consisted of two acceptable manoeuvres. The system was programmed to give instructive messages after every manoeuvre. The device was programmed to reject manoeuvres without a peak (peak expiratory flow time $>120 \mathrm{~ms}$ ), with a slow start (back extrapolated volume $>150 \mathrm{ml}$ ) or with cough or an early termination. A warning message was also given if any of these occurred and the subject was instructed to repeat the manoeuvre. Before and after every monitoring week, five syringe checks and two spirometric manoeuvres by a field technician were performed. The syringe check had to be within $3.5 \%$ for all five checks. FVC and $\mathrm{FEV}_{1}$ of the technician had to be within $6 \%$ and PEF within $15 \%$ of the mean value of the technician.

Baseline characteristics were collected with a questionnaire, including subject biometry and daily medication use. Height and age were used to calculate predicted values for $\mathrm{FEV}_{1}, \mathrm{FVC}$ and PEF, using sex-specific equations. ${ }^{20}$ Information on reliever medication use was collected with a daily questionnaire. In this questionnaire, participants recorded the use of medication and occurrence of symptoms before the lung function tests. The focus is on $\mathrm{FEV}_{1}$, since this is the least effort dependent variable from the available indices, has good reproducibility and is linearly related to the severity of airways obstruction. ${ }^{21}$

\section{Air pollution exposure}

Procedures of air pollution measurements have been reported before. ${ }^{15} 16$ Briefly, we measured mass and number concentration at an urban background central site in each city, near the subject's home outdoors and in the subject's home. Outdoor 
and indoor monitoring was successively carried out at each subject's home for a week, whereas the central site monitoring was running continuously during the whole study period. Particle number concentration (PNC) was continuously monitored with condensation particle counters (TSI 3022A, TSI Inc., St. Paul, Minnesota, USA). Twenty-four-hour average particle mass concentration was measured with Harvard impactors with a $50 \%$ size cut-off at $2.5 \mu \mathrm{m}\left(\mathrm{PM}_{2.5}\right)$ and at $10 \mu \mathrm{m}\left(\mathrm{PM}_{10}\right)$. After weighing, the absorbance of the $\mathrm{PM}_{2.5}$ filters was determined using reflectometry. The same instruments and standard operating procedures (SOP) were used at the central site and the home measurements in the four cities. PNC was transformed to "noon-to-noon" $24 \mathrm{~h}$ means, to coincide with the $\mathrm{PM}_{2.5}$ measurements. Meteorological data (ambient temperature, relative humidity) and data on gaseous air pollution (nitric oxide, nitrogen dioxide, carbon monoxide, sulphur dioxide and ozone) were obtained from existing national monitoring networks.

\section{Quality assurance/quality control}

Air pollution and health measurements were conducted according to common SOPs. A training workshop was organised before the start of the fieldwork and site visits were implemented during the fieldwork to identify aberrations from SOP.

\section{Data analysis}

All analyses were performed per city to allow for differences in associations of, for example, weather variables with lung function between the four cities. Linear regression was used to obtain centre-specific effect estimates, controlling for between-subject differences in lung function using a randomeffect approach. The confounder model further consisted of supervision of the test (yes/no), an indicator variable for season (spring, summer, autumn, winter), time of day (morning, lunch, evening), ambient temperature and humidity. Adjustment for autocorrelation was performed by including a first order autoregressive term (AR-1) in the covariance. For every centre, the best confounder model for temperature and relative humidity was identified for $\mathrm{FEV}_{1}$ starting with a model that included the other indicator variables in the model, but not air pollution. Shape of the association was explored using nonparametric loess functions ${ }^{22}$ with spans from 0.6 to 1 . Previous day (lag 0 ) and the successive previous days (lag 1, lag 2 and lag 3) for temperature and relative humidity were evaluated. Based on the lowest Akaike's Information Criterion and the $\mathrm{FEV}_{1}$ covariate plot, an adequate fit was chosen.

We assessed same-day (lag 0 , from yesterday noon to today noon) and previous-day (air pollution and weather) exposures (lag 1-3 days). For indoor and outdoor home environments, exposures up to lag 2 were analysed since longer lags involved too many missing data. Coarse particle concentrations $\left(\mathrm{PM}_{\text {coarse }}\right)$ were calculated by subtracting $\mathrm{PM}_{2.5}$ from $\mathrm{PM}_{10}$. Effect estimates were calculated for an increase of $20 \mu \mathrm{g} / \mathrm{m}^{-3}$ $\mathrm{PM}_{10}, 20 \mu \mathrm{g} / \mathrm{m}^{-3} \mathrm{PM}_{2.5}, 10000$ particles $/ \mathrm{cm}^{-3} \mathrm{PNC}, 2 \times 10^{-5} / \mathrm{m}^{-1}$ absorbance and $20 \mu \mathrm{g} / \mathrm{m}^{-3}$ coarse particles based on the interquartile ranges of the central site air pollution levels.

For PNC we also analysed hourly data. We assessed the average concentration of $1,4,8$ and $12 \mathrm{~h}$ before the test.

To obtain combined effect estimates, the inverse of the variances of the city-specific estimates were used as weights to calculate a weighted mean of the city-specific slopes.

Sensitivity analyses were performed by excluding tests with a high $(>10 \%)$ coefficient of variation within the test, subjects with $<10$ tests, smokers, and subjects with low variation in exposure during the measurement week (less than the 5 th percentile: $3.98 \mu \mathrm{g} / \mathrm{m}^{-3}$ for $\mathrm{PM}_{2.5}, 4200$ particles $/ \mathrm{cm}^{-3}$ for PNC and $0.54 \mu \mathrm{g} / \mathrm{m}^{-3}$ for coarse particles). Furthermore, we excluded observations below the 5 th and above the 95 th percentile per city for the weather variables and above the 95th percentile for air pollution. Analyses were also performed separately for the three test times of the day to account for different time activity patterns before these time points. Exploratory analysis was performed with S-plus 2000 (Professional Edition for Windows, Release 1; Mathsoft Engineering \& Education, Inc. Cambridge, Massachusetts, USA) while the final analysis of the air pollution effects was performed using mixed-effects models (PROC MIXED) in SAS V.8.02 (SAS Institute Inc., Cary, North Carolina, USA).

\section{RESULTS}

\section{Panel characteristics}

Data from 135 subjects were used in the analysis (table 1). Overall, 69\% of the participants were female. Mean age and age range were about the same in all cities. Three subjects in Athens were slightly below the recruitment criterion of $\geqslant 35$ years. Overall, more subjects had doctor-diagnosed asthma (69\%), especially in Helsinki and Birmingham, than COPD (27\%).

About half of the panel consisted of ex-smokers. Four subjects were currently smokers and six subjects were exposed to smoke in their home. The majority of the panel (77\%) used reliever medication. Of the 22 subjects who were prescribed oral steroids, five of them were prescribed oral steroids for regular use. Inhaled glucocorticosteroids were used by 113 (83\%) of the subjects. Of those, seven subjects were prescribed a daily dose of $\geqslant 1500 \mu \mathrm{g}(750 \mu \mathrm{g}$ for the more potent fluticasone). These seven subjects and the five subjects using oral steroids for regular use were considered as having severe disease. About $30 \%$ of the panel used glucocorticosteroids as needed (and therefore considered as mild), but only very few subjects (7.4\%) actually used glucocorticosteroids during the measurement week.

Twenty-nine subjects (22\%) worked outside their home, especially from Amsterdam and Birmingham. Those who worked outside their home, worked on average $19 \mathrm{~h} /$ week.

\section{Lung function}

A mean of 17.8 tests per person out of a possible 21 tests (85\%) was available for analysis. Failure to perform the test and store test results occasionally, resulted in 14 subjects with $<10$ tests, of which two subjects were excluded because of only one available test. In 131 cases two consecutive tests were performed within 30 minutes. Since $90 \%$ were within 7 minutes, these tests were considered repetitions and treated as one test. In 240 cases subjects performed the test outside the predefined time windows. Since most of these tests $(n=171)$ were just outside the predefined time windows, we included tests performed within $1 \mathrm{~h}$ of the original time window.

The mean percentage of the predicted $\mathrm{FEV}_{1}$ was lower in Athens and Birmingham compared with Helsinki and Amsterdam. This was also true for PEF and FVC, especially in Athens (table 2). For 16 subjects (three in Helsinki, six in Athens, four in Amsterdam and three in Birmingham) measured $\mathrm{FEV}_{1}$ was between 30 and $50 \%$ of the predicted $\mathrm{FEV}_{1}$. One subject's $\mathrm{FEV}_{1}$ was below $30 \%$ of the predicted value. Hence, 17 subjects would be classified as severe or moderate/severe according to the global initiative for chronic obstructive lung disease criteria for COPD. 
Table 1 Characteristics of four European panels of patients with chronic respiratory disease

\begin{tabular}{|c|c|c|c|c|}
\hline & Helsinki & Athens & Amsterdam & Birmingham \\
\hline & $(n=36 *)$ & $\left(\mathrm{n}=34^{*}\right)$ & $\left(n=36^{*}\right)$ & $(n=29 *)$ \\
\hline Male/female & $6 / 30$ & $19 / 15$ & $10 / 26$ & $7 / 22$ \\
\hline Age $\uparrow$ & $63.5(36-85)$ & $62.2(33-84)$ & $63.3(46-77)$ & $60.1(37-76)$ \\
\hline Body mass index $\dagger$ & $24.8(19-32)$ & $27.9(19-44)$ & $26.8(19-41)$ & $27.5(19-46)$ \\
\hline Asthma, $\mathrm{n}(\%)$ & $32(89)$ & $18(53)$ & $15(42)$ & $28(97)$ \\
\hline COPD, n (\%) & $4(11)$ & $16(47)$ & $13(36)$ & $2(6.9)$ \\
\hline $\begin{array}{l}\text { Other respiratory } \\
\text { disease, } \mathrm{n}(\%) \ddagger\end{array}$ & $0(0)$ & $0(0)$ & $17(47)$ & $0(0)$ \\
\hline \multicolumn{5}{|l|}{ Smoking status } \\
\hline Never smoker, n (\%) & $26(72)$ & $14(41)$ & $13(36)$ & $15(52)$ \\
\hline Current, n (\%) & $0(0)$ & $1(3)$ & $0(0)$ & $3(10)$ \\
\hline Ex-smoker, n (\%) & $10(28)$ & $20(59)$ & $23(64)$ & $14(48)$ \\
\hline $\begin{array}{l}\text { ETS§ exposure at } \\
\text { home, } \mathrm{n}(\%)\end{array}$ & $0(0)$ & $5(14.7)$ & $0(0)$ & $1(3.4)$ \\
\hline \multicolumn{5}{|l|}{ Medication use } \\
\hline $\begin{array}{l}\text { Short-acting } \beta_{2} \\
\text { agonist, } \mathrm{n}(\%)\end{array}$ & $24(67)$ & $9(26)$ & $16(44)$ & $28(97)$ \\
\hline $\begin{array}{l}\text { Reliever medication, n } \\
(\%) \uparrow\end{array}$ & $29(81)$ & $21(62)$ & $25(69)$ & $29(100)$ \\
\hline $\begin{array}{l}\text { Inhaled } \\
\text { glucocorticosteroids, } \\
\text { n (\%) }\end{array}$ & $34(94)$ & $28(82)$ & $27(75)$ & $24(83)$ \\
\hline $\begin{array}{l}\text { Oral } \\
\text { glucocorticosteroids, } \\
\text { n (\%) }\end{array}$ & 5 (14) & $5(15)$ & $6(17)$ & $6(21)$ \\
\hline \multicolumn{5}{|l|}{$\begin{array}{l}\text { On need medication } \\
\text { use }\end{array}$} \\
\hline $\begin{array}{l}\text { Short-acting } \beta_{2} \\
\text { agonist, } \mathrm{n}(\%)\end{array}$ & $18(50)$ & $8(24)$ & $14(39)$ & $28(97)$ \\
\hline $\begin{array}{l}\text { Reliever medication, } \mathrm{n} \\
(\%) \text { ฯ }\end{array}$ & $22(61)$ & $21(62)$ & $18(50)$ & $29(100)$ \\
\hline $\begin{array}{l}\text { Inhaled } \\
\text { glucocorticosteroids, } \\
\text { n (\%) }\end{array}$ & $6(17)$ & $18(53)$ & $7(19)$ & $5(17)$ \\
\hline $\begin{array}{l}\text { Oral } \\
\text { glucocorticosteroids, } \\
\text { n (\%) }\end{array}$ & $3(8)$ & $5(15)$ & $4(11)$ & $5(17)$ \\
\hline
\end{tabular}

*Total subjects in panel.

†Given as mean and (range), body mass index (BMI) is calculated as weight $(\mathrm{kg}) \times$ height $(\mathrm{m})^{-2}$.

\$Mainly defined as chronic non-specific lung disease in the Netherlands (a diagnosis that was formerly used for both asthma and chronic obstructive pulmonary disease). $\S$ Environmental tobacco smoke.

-Includes short-acting $\beta_{2}$ agonist, long-acting $\beta_{2}$ agonist, anticholinergic drugs and combination of an anticholinergic drug and a $\beta_{2}$ agonist.

A diurnal pattern for lung function was observed with highest $\mathrm{FEV}_{1}$ during lunch. The within-test coefficient of variation $\left(\mathrm{CV}_{\text {within }}\right)$ was low $(<5 \%)$ for $\mathrm{FEV}_{1}, \mathrm{FVC}$ and PEF in all cities (table 2), indicating that the tests were performed satisfactorily. For $\mathrm{FEV}_{1}, 103(4.3 \%)$ tests had a $\mathrm{CV}_{\text {within }}$ of $>10 \%$, 13 had a $\mathrm{CV}_{\text {within }}$ of $>20 \%$. The median within-person variability of $\mathrm{FEV}_{1}$ across the approximately 18 test moments ( $\left.\mathrm{CV}_{\text {between }}\right)$ was $7.4 \%$ and ranged from $1.8 \%$ to $25.9 \%$ between subjects. There was no significant difference between unsupervised tests and tests that were supervised by a technician.

\section{Air pollution concentrations}

Median air pollution concentrations at the central site were lowest in Helsinki and highest in Athens (table 3). The median particle number concentrations were highest at the central site, followed by home outdoor and home indoor concentration, except for Amsterdam. For the central site, home outdoor and home indoor locations $0.5,1.3$ and $1.6 \%$ of the coarse PM concentrations were negative. Most of these values were close to zero. The small number of negative concentrations is likely due to the subtraction of $\mathrm{PM}_{2.5}$ from $\mathrm{PM}_{10}$. Limits of detection and duplicates showed good quality of PM measurements. ${ }^{15}$ Detection limits for $\mathrm{PM}_{2.5}$ and $\mathrm{PM}_{10}$ ranged from 1.1 to $4.7 \mu \mathrm{g} / \mathrm{m}^{3}$ between the four cities. The relative standard deviation calculated from field duplicates ranged from 6 to $9 \%$ for $\mathrm{PM}_{2.5}$ and $\mathrm{PM}_{10} ; 9$ to $24 \%$ for coarse particles across the four cities.

The within-subject exposure variation was smaller than reported in table 3, as subjects participated for 1 week. For most subjects, there was a considerable range in concentration. On average, the within-subject range of central site $\mathrm{PM}_{2.5}$ concentrations was between $94 \%$ (Athens) and 130\% (Birmingham) of the individual mean $\mathrm{PM}_{2.5}$ concentration. For central site PNC, the average percentage within-subject range was between 63\% (Amsterdam) and 100\% (Helsinki).

City-specific Spearman correlations between particle number and mass at the central site were weak to moderate (range 0.20-0.55 for $\mathrm{PM}_{10}, 0.21-0.47$ for $\mathrm{PM}_{2.5}$ and $0.00-0.39$ for $\mathrm{PM}_{\text {coarse }}$ ). Cityspecific Spearman correlations between concentrations measured at the central site and near the home outdoors ranged from 0.6 to 0.7 (particle number) and 0.8 to $1.0\left(\mathrm{PM}_{2.5}\right) \cdot{ }^{15}$ City-specific Spearman correlation between concentrations measured at the central site and in the home ranged from 0.1 to 0.4 for particle number and 0.3 to 0.8 for $\mathrm{PM}_{2.5}{ }^{16}$

\section{Air pollution effects on lung function}

There was no consistent association between particulate air pollution and lung function ( $\mathrm{FEV}_{1}, \mathrm{PEF}$ and FVC) (table 4, fig 1). There was a positive significant association between $\mathrm{FEV}_{1}$ and home outdoor $\mathrm{PM}_{2.5}$ at lag 0 and lag 1, but no relationship with central site $\mathrm{PM}_{2.5}$ and indoor $\mathrm{PM}_{2.5}$. There was a significant negative association between central site $\mathrm{PM}_{2.5}$ and lung function at lag 3. Concentrations measured inside or outside the home were not more strongly related to lung function than concentrations measured at the central site. Although cityspecific effect estimates ranged from negative to positive, confidence intervals overlapped for PNC and $\mathrm{PM}_{2.5}$ (fig 2) and other air pollutants (data not shown).

The lack of an association between lung function and air pollution was robust for various modifications in the model. Removing smoking subjects $(n=4)$, subjects with $<10$ tests $(n=14)$, tests with a $>10 \%$ coefficient of variation $(n=103)$ or subjects with a low variation in exposure did not change the observed associations meaningfully. The basic model, with subject as a fixed or random effect but without confounders showed practically the same associations as the model with confounders. Removing high air pollution and high and low temperature and relative humidity days did not change the observed associations: effect estimates for the lag 0 concentrations at the central site of PNC and $\mathrm{PM}_{2.5}$ on $\mathrm{FEV}_{1}$ were $11(-3$ to 24 ) and 23 ( -4 to 49$) \mathrm{ml} / \mathrm{s}^{-1}$, respectively.

Negative associations between lung function and air pollution could be masked by increased medication use on high air pollution days. However, adding the "as needed" use of $\beta_{2}$ agonist in the model did not reveal such an effect. No consistent associations between $\mathrm{FEV}_{1}$ at different times of day and air pollution were found (data not shown).

When the analysis was restricted to the 93 asthmatic subjects in the panel, no association between air pollution and $\mathrm{FEV}_{1}$ was found. The combined effect estimate at central site lag 0 for $\mathrm{FEV}_{1}$ and $\mathrm{PM}_{2.5}$ was 17 ( -10 to 43 ) and for PNC 13 ( -1 to 27 ).

When the 29 working subjects were excluded, associations between air pollution and lung function were unchanged. The 
Table 2 Descriptive statistics of the lung function variables in the four Relationship between Ultrafine and fine Particulate matter in Indoor and Outdoor air and respiratory Health centres

\begin{tabular}{|c|c|c|c|c|c|}
\hline & & Helsinki & Athens & Amsterdam & Birmingham \\
\hline & & $\left(n=645^{*}\right)$ & $(n=604 *)$ & $(n=600 *)$ & $\left(n=562^{*}\right)$ \\
\hline & & Mean & Mean & Mean & Mean \\
\hline $\mathrm{FEV}_{1}$ & 1 & 2.09 & 1.85 & 2.21 & 1.93 \\
\hline PRED. $\dagger$ FEV $_{1}$ & I & 2.42 & 2.60 & 2.62 & 2.58 \\
\hline$\%$ PRED. FEV ${ }_{1}$ & $\%$ & 86.4 & 71.0 & 84.4 & 74.9 \\
\hline $\mathrm{CV}_{\text {within }} \mathrm{FEV}_{1}$ & $\%$ & 3.0 & 3.7 & 3.6 & 3.2 \\
\hline $\mathrm{CV}_{\text {between }} \S \mathrm{FEV}_{1}$ & $\%$ & 5.7 & 8.6 & 7.0 & 8.3 \\
\hline PEF & $\mathrm{l} / \mathrm{s}^{-1}$ & 6.00 & 5.09 & 5.87 & 5.42 \\
\hline PRED. PEF & $1 / s^{-1}$ & 6.34 & 6.90 & 6.72 & 6.62 \\
\hline \%PRED. PEF & $\%$ & 94.6 & 73.8 & 87.4 & 81.9 \\
\hline $\mathrm{CV}_{\text {within }}$ PEF & $\%$ & 3.5 & 4.9 & 4.3 & 4.1 \\
\hline $\mathrm{CV}_{\text {between }} \mathrm{PEF}$ & $\%$ & 6.6 & 11.4 & 8.5 & 9.6 \\
\hline FVC & 1 & 2.65 & 2.40 & 2.92 & 2.60 \\
\hline PRED. FVC & I & 2.93 & 3.24 & 3.20 & 3.13 \\
\hline \%PRED. FVC & $\%$ & 90.4 & 74.0 & 91.3 & 83.2 \\
\hline $\mathrm{CV}_{\text {within }} \mathrm{FVC}$ & $\%$ & 3.7 & 4.1 & 3.8 & 4.0 \\
\hline $\mathrm{CV}_{\text {between }} \mathrm{FVC}$ & $\%$ & 6.4 & 8.1 & 7.8 & 10.4 \\
\hline
\end{tabular}

*Total amount of tests.

†PRED is predicted value using subjects' height and age.

\$Mean coefficient of variation between two consecutive blows within test.

$\S$ Mean coefficient of variation of best value between tests.

CV, coefficient of variation; FEV 1 , forced expiratory volume in 1 second; FVC, forced vital capacity; PEF, peak expiratory flow.

combined effect estimate at central site lag 0 for $\mathrm{FEV}_{1}$ and $\mathrm{PM}_{2.5}$ was 23 ( -4 to 49 ) and for PNC 11 ( -3 to 24 ).

\section{Hourly particle number concentrations}

Combined effect estimates were essentially zero for $1 \mathrm{~h}, 4 \mathrm{~h}, 8 \mathrm{~h}$ and $12 \mathrm{~h}$ average PNC concentrations preceding the test for central site and indoor. For home outdoor PNC, small significant positive associations were found, consistent with the association observed for the concurrent $24 \mathrm{~h}$ average concentration. For $\mathrm{FEV}_{1}$, combined effect estimates for the average PNC of the previous $4 \mathrm{~h}$ were 0.3 ( -6 to 6 ), 6.5 (0.4 to 13) and 0.5 (-3 to 4$) \mathrm{ml} / \mathrm{s}^{-1}$ per 10000 particles $/ \mathrm{cm}^{3}$ for the central site, home outdoor and indoor location.

\section{DISCUSSION}

No consistent associations between lung function and particulate matter air pollution were found in four panels of subjects with predominantly mild to moderate asthma or COPD.

Table 3 Daily (24 h noon-to-noon) median $24 \mathrm{~h}$ average air pollution concentration and meteorology in the four Relationship between Ultrafine and fine Particulate matter in Indoor and Outdoor air and respiratory Health centres

\begin{tabular}{|c|c|c|c|c|c|}
\hline & & Helsinki & Athens & Amsterdam & Birmingham \\
\hline & & Median (range) & Median (range) & Median (range) & Median (range) \\
\hline \multicolumn{6}{|l|}{ Central site } \\
\hline PNC & $1000 \mathrm{~cm}^{-3}$ & 12.5 (2.1 to 44.5$)$ & 20.2 (3.3 to 66.1$)$ & 18.3 (8.5 to 44.4$)$ & 19.2 (2.2 to 50.8$)$ \\
\hline $\mathrm{PM}_{10}$ & $\mu \mathrm{g} / \mathrm{m}^{-3}$ & $12.4(0$ to 156.4$)$ & 51.7 (8.5 to 158.7$)$ & $26.6(7.4$ to 126$)$ & 16.6 (2.8 to 126.2$)$ \\
\hline $\mathrm{PM}_{2.5}$ & $\mu \mathrm{g} / \mathrm{m}^{-3}$ & $7.4(0$ to 33.2$)$ & 22.7 (2.4 to 79.1$)$ & 16.7 (4.0 to 103.4 ) & $8.4(0.7$ to 71.9$)$ \\
\hline $\mathrm{PM}_{\text {coarse }}$ & $\mu \mathrm{g} / \mathrm{m}^{-3}$ & $4.3(-1.7$ to 152.6$)$ & $28.8(0.7$ to 126.4$)$ & $9.2(-6.4$ to 24.2$)$ & $7.0(-3.7$ to 118.9$)$ \\
\hline Absorbance & $10^{-5} / \mathrm{m}^{-1}$ & $1.2(0.2$ to 3.8$)$ & $3.5(0.9$ to 8.4$)$ & $1.9(0.5$ to 7.2$)$ & $1.3(0.2$ to 4.9$)$ \\
\hline \multicolumn{6}{|l|}{ Home outdoor } \\
\hline PNC & $1000 \mathrm{~cm}^{-3}$ & 4.6 (1.2 to 22.2$)$ & 15.5 (1.0 to 64.2$)$ & $24.8(10$ to 114.4$)$ & 15.7 (6.5 to 42.4$)$ \\
\hline $\mathrm{PM}_{10}$ & $\mu \mathrm{g} / \mathrm{m}^{-3}$ & 12.2 (1.9 to 51.5$)$ & $44.9(9.9$ to 165.1$)$ & 28.8 (9.4 to 121.3$)$ & 17.2 (4.6 to 71.6$)$ \\
\hline $\mathrm{PM}_{2.5}$ & $\mu \mathrm{g} / \mathrm{m}^{-3}$ & $8.4(1.4$ to 33$)$ & 20.3 (5.5 to 103.2 ) & 17.2 (4.6 to 105.3 ) & 9.8 (1.7 to 58$)$ \\
\hline $\mathrm{PM}_{\text {coarse }}$ & $\mu \mathrm{g} / \mathrm{m}^{-3}$ & $3.5(-3.7$ to 28.5$)$ & $21.3(-7.7$ to 105.1$)$ & $10.7(-0.1$ to 23.8$)$ & $7.6(-3.5$ to 52$)$ \\
\hline Absorbance & $10^{-5} / \mathrm{m}^{-1}$ & $1.2(0.3$ to 5.6$)$ & $2.9(0.8$ to 9.2$)$ & $2.2(0.6$ to 7.9$)$ & $1.3(0.4$ to 5.5$)$ \\
\hline \multicolumn{6}{|l|}{ Home indoor } \\
\hline PNC & $1000 / \mathrm{cm}^{-3}$ & $3.7(0.4$ to 58.9$)$ & $11.9(0.8$ to 156.3$)$ & $12.6(4.1$ to 152.1$)$ & $10.4(2.1$ to 97.4$)$ \\
\hline $\mathrm{PM}_{10}$ & $\mu \mathrm{g} / \mathrm{m}^{-3}$ & $11.1(2.7$ to 40.6$)$ & 32.6 (5.5 to 77.2$)$ & $20.9(6.1$ to 106.8$)$ & 14.2 (4.3 to 509.1$)$ \\
\hline $\mathrm{PM}_{2.5}$ & $\mu \mathrm{g} / \mathrm{m}^{-3}$ & $6.5(1.5$ to 35.1$)$ & 20.3 (3.3 to 51.5$)$ & 12.9 (4.0 to 98.5$)$ & 7.3 (1.4 to 512.3$)$ \\
\hline $\mathrm{PM}_{\text {coarse }}$ & $\mu \mathrm{g} / \mathrm{m}^{-3}$ & $4.2(-4.2$ to 31.1$)$ & $11.8(-0.9$ to 56.8$)$ & $6.9(-1.7$ to 55.5$)$ & $6.1(-3.2$ to 86.2$)$ \\
\hline Absorbance & $10^{-5} / \mathrm{m}^{-1}$ & $0.8(0.1$ to 7.5$)$ & $2.7(0.7$ to 8.6$)$ & $1.8(0.3$ to 11$)$ & $0.9(0.1$ to 5.4$)$ \\
\hline \multicolumn{6}{|l|}{ Network } \\
\hline Temperature & ${ }^{\circ} \mathrm{C}$ & $2.0(-22.8$ to 25.6$)$ & $15.0(-3.1$ to 33.2$)$ & $9.1(-6.1$ to 25.3$)$ & $9.2(-1.4$ to 26.9$)$ \\
\hline $\begin{array}{l}\text { Relative } \\
\text { humidity }\end{array}$ & $\%$ & 80.7 (36.5 to 100$)$ & 66.1 (21.8 to 93.2$)$ & 80.8 (38.5 to 98.7$)$ & $79.3(45.8$ to 97.9$)$ \\
\hline
\end{tabular}

$\mathrm{PM}_{2.5}$, particulate matter of $\leqslant 2.5 \mu \mathrm{g} ; \mathrm{PM}_{10}$, particulate matter of $\leqslant 10 \mu \mathrm{g} ; \mathrm{PNC}$, particle number concentration. 
Figure 1 Combined effect estimates $(\Delta$ in $\mathrm{ml} / \mathrm{s}^{-1}$ ) with $95 \% \mathrm{Cl}$ for the association of forced expiratory volume in 1 second and air pollution components at central site, home outdoors and home indoors. $\mathrm{PM}_{2.5}$, particulate matter $\leqslant 2.5 \mu \mathrm{m}$; $\mathrm{PM}_{10}$, particulate matter $\leqslant 10 \mu \mathrm{m} ; \mathrm{PNC}$, particle number concentration.
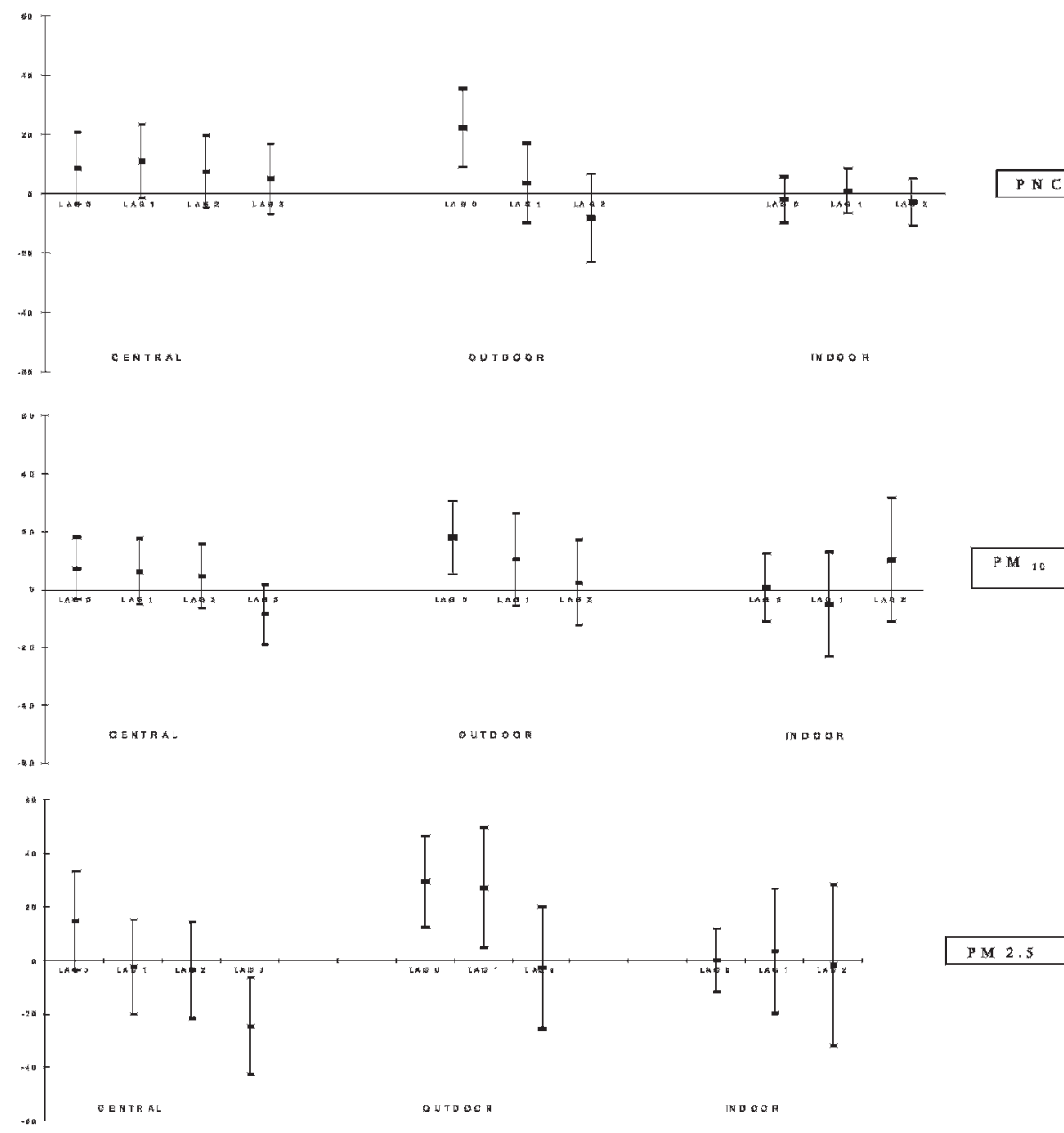
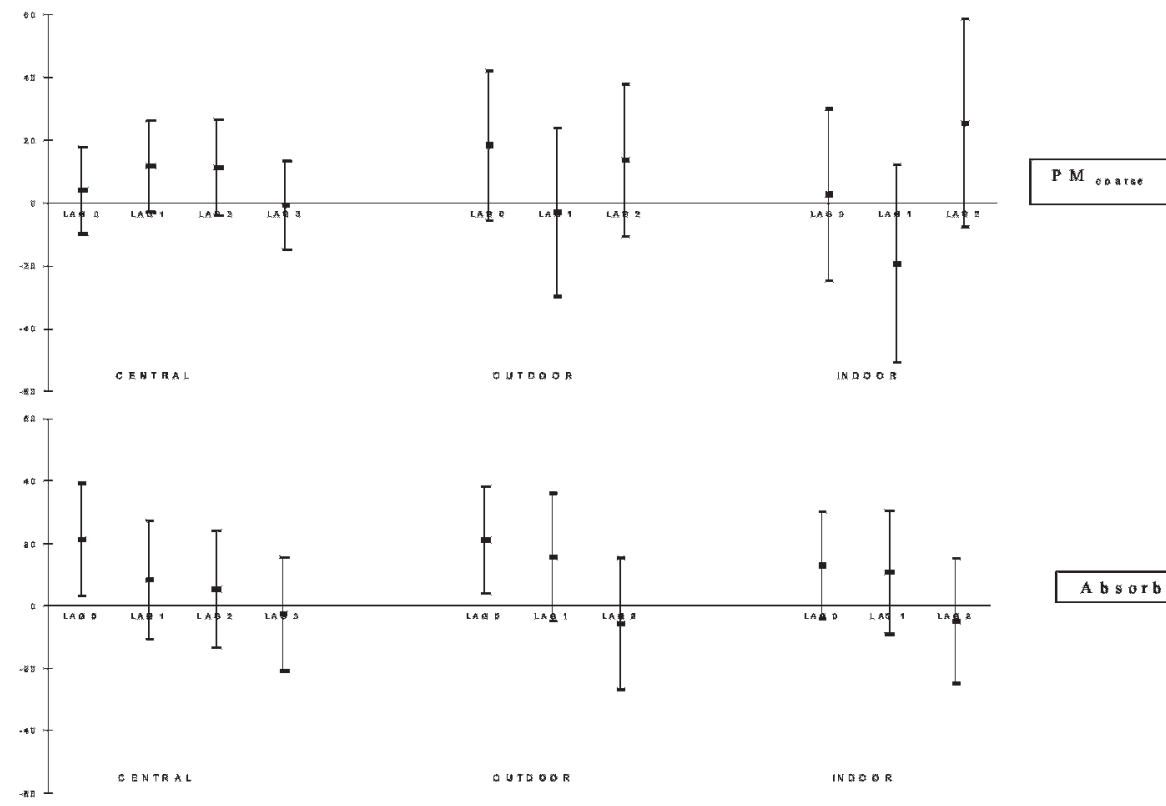

A bsorbance

Associations did not become stronger when exposure was characterised using concentrations measured near/in the home of study participants instead of at a central site.

This study is not in agreement with earlier studies, since no effect from particle mass or number was observed. However, in previous studies that measured both particle mass and number, the observed effects on spirometry varied substantially. A
German study in 27 asthmatic adults in Erfurt found associations of both $\mathrm{PM}_{10}$ and particle number with daily PEF, but the associations for ultrafine particle numbers were stronger than those of $\mathrm{PM}_{10}{ }^{13}$ In a Finnish study associations were stronger for particle number when using daily peak-flow measurements ${ }^{11}$ and stronger for accumulation mode particles when using PEF measured biweekly with a spirometer in the same panel of 
Table 4 Combined effect estimates $(\Delta)$ with $95 \% \mathrm{Cl}$ for the association of air pollution and forced expiratory volume in 1 second $\left(\mathrm{FEV}_{1}\right)$, peak expiratory flow (PEF) and forced vital capacity (FVC) in four panels of symptomatic subjects

\begin{tabular}{|c|c|c|c|}
\hline & $\mathrm{FEV}_{1}$ & PEF & FVC \\
\hline & $\Delta \dagger(95 \% \mathrm{Cl})$ & $\Delta \dagger(95 \% \mathrm{Cl})$ & $\Delta \dagger(95 \% \mathrm{Cl})$ \\
\hline \multicolumn{4}{|l|}{ Central site } \\
\hline PNC lag 0 & $9(-3$ to 21$)$ & $22(-16$ to 60$)$ & $1(-17$ to 18$)$ \\
\hline PNC lag 1 & $11(-1$ to 24$)$ & $14(-25$ to 53$)$ & $13(-5$ to 31$)$ \\
\hline PNC lag 2 & $8(-4$ to 20$)$ & $4(-34$ to 42$)$ & $12(-5$ to 30$)$ \\
\hline PNC lag 3 & $5(-7$ to 17$)$ & $-4(-40$ to 33$)$ & $11(-6$ to 28$)$ \\
\hline $\mathrm{PM}_{2.5}$ lag 0 & $15(-3$ to 34$)$ & $25(-32$ to 81$)$ & $20(-7$ to 48$)$ \\
\hline $\mathrm{PM}_{2.5} \operatorname{lag} 1$ & $-2(-20$ to 16$)$ & $-23(-79$ to 32$)$ & $-16(-43$ to 11$)$ \\
\hline $\mathrm{PM}_{2.5} \operatorname{lag} 2$ & $-4(-22$ to 15$)$ & $-14(-70$ to 41$)$ & $-16(-42$ to 10$)$ \\
\hline $\mathrm{PM}_{2.5} \operatorname{lag} 3$ & $-24(-42$ to -6$)$ & $-53(-108$ to 1$)$ & $-28(-53$ to -3$)$ \\
\hline \multicolumn{4}{|c|}{ Home outdoor } \\
\hline PNC lag 0 & 22 (9 to 36 ) & 44 (5 to 83 ) & 19 (0 to 38$)$ \\
\hline PNC lag 1 & $4(-10$ to 17$)$ & $17(-28$ to 62$)$ & $-7(-27$ to 13$)$ \\
\hline PNC lag 2 & $-8(-23$ to 7$)$ & $-29(-77$ to 19$)$ & $-13(-34$ to 7$)$ \\
\hline $\mathrm{PM}_{2.5} \operatorname{lag} 0$ & 30 (13 to 47$)$ & $48(-6$ to 101$)$ & $16(-10$ to 41$)$ \\
\hline $\mathrm{PM}_{2.5} \operatorname{lag} 1$ & 27 (5 to 50$)$ & $32(-34$ to 99$)$ & $16(-15$ to 48$)$ \\
\hline $\mathrm{PM}_{2.5}$ lag 2 & $-3(-25$ to 20$)$ & $-7(-77$ to 63$)$ & $-13(-44$ to 18$)$ \\
\hline \multicolumn{4}{|l|}{ Home indoor } \\
\hline PNC lag 0 & $-2(-10$ to 6$)$ & $-4(-27$ to 20$)$ & $-7(-18$ to 4$)$ \\
\hline PNC lag 1 & $1(-6$ to 9$)$ & $-5(-29$ to 19$)$ & $-1(-12$ to 9$)$ \\
\hline PNC lag 2 & $-3(-11$ to 5$)$ & $5(-20$ to 29$)$ & $-5(-15$ to 5$)$ \\
\hline $\mathrm{PM}_{2.5} \operatorname{lag} 0$ & $0(-12$ to 12$)$ & $-12(-45$ to 20$)$ & $0(-19$ to 19$)$ \\
\hline $\mathrm{PM}_{2.5} \operatorname{lag} 1$ & $4(-20$ to 27$)$ & $-13(-83$ to 57$)$ & $-3(-34$ to 29$)$ \\
\hline $\mathrm{PM}_{2.5}$ lag 2 & $-2(-32$ to 29$)$ & $0(-96$ to 95$)$ & $-13(-53$ to 28$)$ \\
\hline
\end{tabular}

$\uparrow$ Absolute change $(\Delta)$ in $\mathrm{ml}(\mathrm{FVC}), \mathrm{ml} / \mathrm{s}^{-1}\left(\mathrm{PEF}, \mathrm{FEV}_{1}\right)$ for an increase of 10000 particles $/ \mathrm{cm}^{-3}$ for PNC and $20 \mu \mathrm{g} / \mathrm{m}^{-3}$ for $\mathrm{PM}_{2.5}$, based on the interquartile ranges of the central site air pollution levels in the four cities.

$\mathrm{PM}_{2.5}$, particulate matter $\leqslant 2.5 \mu \mathrm{g}$; PNC, particle number concentration.

57 asthmatic adults. ${ }^{12}$ Another study in 44 adult patients with COPD found borderline significant associations of PEF with $\mathrm{PM}_{10}$ only. ${ }^{10}$ Statistically significant associations with $\mathrm{PM}_{10}$, but not with particle number, were observed in a Finnish panel of 39 asthmatic schoolchildren. ${ }^{8}$ In another study with 49 Finnish schoolchildren associations varied by lag. ${ }^{9}$

Many panel studies of short-term effects of outdoor air pollution relied on measurement of peak flow using Mini Wright Peak Flow meters. In the current study, we used a home spirometer allowing data storage so that the subjects did not have to record test results in a diary. As recording of peak flow in diaries may be unreliable $e^{23}$ and compliance with paper diaries poor, ${ }^{25}$ the use of a spirometer that stored lung function data is a major advantage of this study. Furthermore, portable spirometers allow monitoring of $\mathrm{FEV}_{1}$ and FVC next to PEF. $\mathrm{PEF}, \mathrm{FEV}_{1}$ and FVC measure different aspects with PEF being more a measure of large airway flow. Home spirometry has been shown to be feasible, even in 5-10-year-old asthmatic children: $94 \%$ compliance and $85 \%$ reproducible lung function tests. ${ }^{26}$ In the current study, compliance was good and coefficients of variation low, suggesting that the tests have been performed properly. The majority of tests were not supervised, but we did not find a significant difference between supervised and nonsupervised tests. A disadvantage of the use of a home spirometer is the smaller number of observations per subject compared with diary studies using the cheaper Mini Wright meter. Compared with the published single city panel studies, our study included a larger number of subjects.

Lack of statistical power is an unlikely explanation of the null findings in this study. The standard error of the combined effect estimates was small, for example, for $\mathrm{PM}_{2.5}$ the standard errors were 9,13 and $39 \mathrm{ml} / \mathrm{s}^{-1}$ per $20 \mu \mathrm{g} / \mathrm{m}^{3}$ for $\mathrm{FEV}_{1}, \mathrm{FVC}$ and $\mathrm{PEF}$, respectively (between 0.5 and $0.7 \%$ of the population mean lung function). The few (positive and negative) significant effect estimates were about $1 \%$ of the population mean. We cannot exclude the possibility that smaller effects occurred, but the biological significance of short-term changes $<1 \%$ seems unclear.

The panel included both asthma and COPD patients, in varying ratios in the different cities. This may have contributed to heterogeneity in effect estimates and may potentially have masked an association. However, all panels included a large fraction of asthmatic subjects. Overall, 93 of the 135 subjects were asthmatic. An analysis restricted to the asthmatic subjects also showed no negative association with lung function. An analysis restricted to COPD patients was not possible, because in Helsinki and Birmingham only four and two COPD patients participated. Hence, the power to assess the health effects of air pollution in this group was limited.

The analysis restricted to asthmatics has taken care of one of the main differences between the four panels that may have resulted in heterogeneity in effect estimates. Further, in none of the individual cities, there was evidence of a negative association with lung function. Effect estimates amounted to a change of typically $<1 \%$ of the population mean lung function in individual city analyses (fig 2), with the exception of the positive effect estimates for $\mathrm{PM}_{2.5}$ in Helsinki where a low variability in exposure resulted in wide confidence limits.

Concentrations measured at the central site tended to be higher than in the Finnish studies ${ }^{811} 12$ that did find negative associations with lung function, so low exposure levels are an unlikely explanation. Although we measured both particle mass and number, it is possible that other characteristics of particulate matter were important, for example, surface area.

As people spend most of their time indoors, the characterisation of exposure to air pollution using data obtained at a central site, may result in substantial exposure misclassification. However, indoor and home outdoor particle concentrations were not more strongly associated with lung function than central site air pollution. Exposure misclassification seems an unlikely explanation for the lack of effect of air pollution.

The design of the study, with measurements within one subject performed in a 1-week period, limits the ability to assess lagged exposures. We therefore cannot exclude the possibility that exposures of averaging periods longer than a few days may have affected lung function. Some indication for an association with air pollution lagged 3 days was found in the current study, though this may have been a chance finding. Another disadvantage of the 1-week design is smaller exposure contrasts compared with measurements spread over a longer period. Most subjects, however, had sufficient variation and exclusion of those with small variation did not result in different effect estimates. The smaller contrast in exposure moreover does not result in bias, but in decreased precision.

We attempted to select subjects with moderately severe asthma/COPD, because we anticipated that severe patients might have chronically low lung function with relatively small temporal variation. An analysis of the regular use of oral and inhaled glucocorticosteroids showed that only 11 subjects with severe disease were included in the panel. Five subjects were prescribed oral steroids and seven subjects were on a high regular dose of inhaled steroids, with one of them also on oral steroids. Baseline lung function was $<50 \%$ of predicted for 
Figure 2 Combined and centre-specific effect estimates ( $\Delta$ in $\mathrm{ml} / \mathrm{s}^{-1}$ ) with $95 \% \mathrm{Cl}$ for the association of forced expiratory volume in 1 second $\left(\mathrm{FEV}_{1}\right)$ and air pollution (particle number concentration (PNC) and particulate matter $\leqslant 2.5 \mu \mathrm{g}$ $\left(\mathrm{PM}_{2.5}\right)$ ) components at central site, home outdoors and home indoors. From left to right: Helsinki, Athens, Amsterdam and Birmingham.
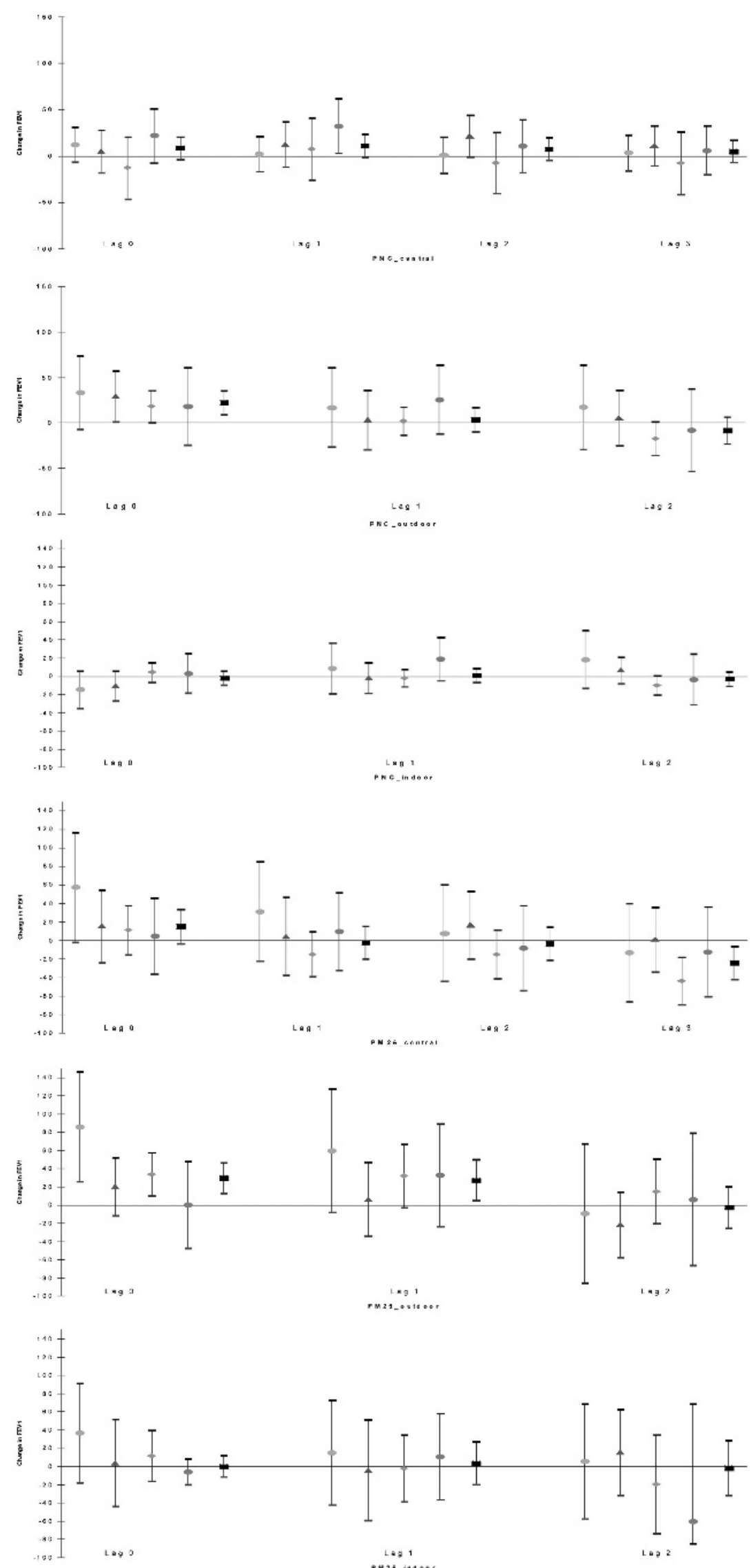
17 subjects. Hence, the majority of subjects probably had mild/ moderate disease.

A potential explanation could be the high use of respiratory medication (94\%), which could have masked any effect of air pollution. Though we adjusted for as-needed medication using a binary variable, we cannot adjust for the potential masking effect of maintenance medication. We did not have daily data on dose of as-needed medication, but most panel studies have successfully evaluated binary variables as well.

In conclusion, no consistent associations between lung function and particulate matter air pollution were found in a group of patients with asthma or COPD across a range of severities. More detailed exposure assessment by using home outdoor and home indoor levels of particulate air pollution instead of central site measurements did not change the observed associations.

Acknowledgements: The project "Relationship between Ultrafine and fine Particulate matter in Indoor and Outdoor air and respiratory Health" was funded by the EU ENVIRONMENT and CLIMATE Research Programme, contract QLRT-2001-00452. The project was coordinated by the Institute of Risk Assessment Sciences, with additional funding from the Municipal Health Service Amsterdam.

The contribution of the following persons to the fieldwork of the project is gratefully acknowledged: Niilo Kalakoski, Jyrki Martikainen, Arto Puustinen, Marko Vallius (Helsinki), Ino Vei, Evangelos Akylas, Dimitrios Papagiannis, Antonios Foutougios, Spyros Lykoudis, Elena Arvanitaki, Vana Athanasiadi, Maria Lianou (Athens), Kees Meliefste, Hans Jongsma, Marjan Tewis, Nicolette van der Heijden-de Hartog, Jack van Gommeren, Gerard Kos, Piet Jongejan, Joop van Wijnen (Amsterdam) and Steve Thomas (Birmingham).

Competing interests: None.

Ethics approval: Medical ethical clearance was acquired from the local medical ethics committees in all centres before the start of the recruitment.

Patient consent: Obtained.

Provenance and peer review: Not commissioned; externally peer reviewed.

\section{REFERENCES}

1. Brunekreef B, Holgate ST. Air pollution and health. Lancet 2002;360:1233-42.

2. Donaldson K, Stone V, Clouter A, et al. Ultrafine particles. Occup Environ Med 2001;58:211-6, 199.

3. Oberdorster G, Finkelstein JN, Johnston C, et al. Acute pulmonary effects of ultrafine particles in rats and mice. Res Rep Health Eff Inst 2000;(96):5-74; disc 75-86.

4. de Hartog JJ, Hoek G, Mirme A, et al. Relationship between different size classes of particulate matter and meteorology in three European cities. J Environ Monit 2005; 7:302-10.
5. Pekkanen J, Kulmala M. Exposure assessment of ultrafine particles in epidemiologic time-series studies. Scand J Work Environ Health 2004;30(Suppl 2):9-18.

6. Jaques PA, Kim CS. Measurement of total lung deposition of inhaled ultrafine particles in healthy men and women. Inhal Toxicol 2000;12:715-31.

7. Ferin J, Oberdorster G. Polymer degradation and ultrafine particles: potential inhalation hazards for astronauts. Acta Astronaut 1992;27:257-9.

8. Pekkanen J, Timonen KL, Ruuskanen J, et al. Effects of ultrafine and fine particles in urban air on peak expiratory flow among children with asthmatic symptoms. Environ Res 1997;74:24-33.

9. Tiittanen $\mathbf{P}$, Timonen $\mathrm{KL}$, Ruuskanen J, et al. Fine particulate air pollution, resuspended road dust and respiratory health among symptomatic children. Eur Respir J 1999;13:266-73.

10. Osunsanya T, Prescott G, Seaton A. Acute respiratory effects of particles: mass or number? Occup Environ Med 2001;58:154-9.

11. Penttinen $\mathbf{P}$, Timonen $\mathrm{KL}$, Tiittanen $\mathbf{P}$, et al. Ultrafine particles in urban air and respiratory health among adult asthmatics. Eur Respir J 2001;17:428-35.

12. Penttinen $\mathbf{P}$, Timonen $\mathrm{KL}$, Tiittanen $\mathrm{P}$, et al. Number concentration and size of particles in urban air: effects on spirometric lung function in adult asthmatic subjects. Environ Health Perspect 2001;109:319-23.

13. Peters A, Wichmann HE, Tuch T, et al. Respiratory effects are associated with the number of ultrafine particles. Am J Respir Crit Care Med 1997;155:1376-83.

14. Brunekreef B, Janssen NA, de Hartog JJ, et al. Personal, indoor, and outdoor exposures to PM2.5 and its components for groups of cardiovascular patients in Amsterdam and Helsinki. Res Rep Health Eff Inst 2005;(127):1-70; discussion 71-9.

15. Puustinen A, Hameri K, Pekkanen J, et al. Spatial variation of particle number and mass over four European cities. Atmos Environ 2007;41:6622-36.

16. Hoek G, Kos G, Harrison RM, et al. Indoor-outdoor relationships of particle number and mass in four European cities. Atmos Environ 2008;42:156-69.

17. American Thoracic Society. Standardization of spirometry, 1994 update. Am J Respir Crit Care Med 1995;152:1107-36.

18. Dirksen A, Madsen F, Pedersen OF, et al. Long-term performance of a hand held spirometer. Thorax 1996;51:973-6.

19. Godschalk I, Brackel HJ, Peters JC, et al. Assessment of accuracy and applicability of a portable electronic diary card spirometer for asthma treatment. Respir Med 1996;90:619-22.

20. Quanjer PH, Tammeling GJ, Cotes JE, et al. Lung volumes and forced ventilatory flows. Report Working Party Standardization of Lung Function Tests, European Community for Steel and Coal. Official Statement of the European Respiratory Society. Eur Respir J Supp/ 1993;16:5-40.

21. Enright $\mathbf{P}$, Lebowitz MD, Cockroft D. Physiologic measures: pulmonary function tests. Asthma outcome. Am J Respir Crit Care Med 1994;149:s9-18.

22. Hastie T, Tibshirani R. Generalized additive models. London: Chapman and Hall Ltd., 1990.

23. Chowienczyk PJ, Parkin DH, Lawson CP, et al. Do asthmatic patients correctly record home spirometry measurements? BMJ 1994;309:1618.

24. Hyland ME, Kenyon CA, Allen R, et al. Diary keeping in asthma: comparison of written and electronic methods. BMJ 1993;306:487-9.

25. Stone A, Shiffman S, Schwartz J, et al. Patient compliance with paper and electronic diaries. Control Clin Trials 2003;24:182-99.

26. Pelkonen AS, Nikander K, Turpeinen M. Reproducibility of home spirometry in children with newly diagnosed asthma. Pediatr Pulmonol 2000;29:34-8. 